\title{
perifèria
}

Número 4, julio 2006

www.periferia.name

\section{Individuo, familia y comunidad. Un estudio de caso en Transilvania}

\author{
Míriam Torrens Arnal - Universitat Autònoma de Barcelona ${ }^{1}$
}

\section{Resumen}

Este artículo pretende sintetizar algunos de los aspectos más relevantes de la discusión teórica y metodológica que ha tenido lugar en la disciplina en torno a los estudios de comunidades campesinas. Es a partir del trabajo de campo etnográfico en una comunidad székely de Transilvania que surgen las reflexiones sobre el concepto de comunidad y la naturaleza de la sociedad y cultura campesinas. A través de la etnografía, nos interesa destacar la forma en que las prioridades morales que actúan en los dominios del parentesco y la vecindad, afectan a la economía produciendo diferentes tipos de compromisos. Estos compromisos que son a la vez sociales, individuales, morales y económicos definen una forma de convivir original.

\begin{abstract}
This article is intended to summarize some relevant aspects about the methodological and theoretical debate in the field on peasant communities. The concept of community and the nature of both Peasant Society and Culture arise from the ethnographical fieldwork performed in a székely community in Transilvania. We are interested in understand the commitments through which morality in kinship and neighbourhood affects economy. These commitments are manifold (social, individual, moral and economic) and they define an original way of life.
\end{abstract}

\footnotetext{
${ }^{1}$ Enviar correspondencia a: miriamtorrens@yahoo.es
} 


\section{perifèria}

Número 4, julio 2006

www.periferia.name

La comunidad rural donde se ha llevado a cabo el trabajo de campo se encuentra situada en los altiplanos orientales de Transilvania, entre 600 y 700 metros de altitud, y sus habitantes pertenecen a la minoría székely ${ }^{2}$ de Rumania. Se estima que en Transilvania viven unos 2 millones de húngaros de los cuales 700.000 son székely. La llamada tierra székely (székelyföld) la componen las provincias de Harghita, Mures y Covasna y, en estas provincias, los húngaro hablantes alcanzan el $90 \%$ de la población. La comunidad estudiada computa actualmente unos 300 habitantes que viven en su totalidad de una economía de subsistencia que combina agricultura y ganadería. Estos campesinos son pequeños propietarios que tradicionalmente comparten bosques, tierras y pastos comunales. Como tantos pueblos de la región, cuentan con unas infraestructuras muy deficitarias, con muy mala comunicación con el exterior y con una población muy envejecida. Se trata pues del estudio de una pequeña comunidad rural en el contexto post-socialista de Europa del Este y con la peculiaridad de tratarse de una minoría nacional en Rumania.

La investigación pretende dialogar con los estudios de comunidades campesinas, especialmente de Europa del Este. Por ello, un aspecto central de la tesis gira en torno al concepto de comunidad. Debo confesar que, cuando inicié el trabajo de campo, me interesaba sobre todo la situación rural y los conflictos étnicos de los países post socialistas europeos y no tanto la discusión sobre el concepto de comunidad. Fue precisamente la práctica etnográfica la que me suscitó el interés por la idea de comunidad. El día a día en la comunidad me descubrió de forma experiencial y apenas sin darme cuenta, que la comunidad no era sólo una vieja discusión académica un poco trillada en antropología sino una realidad vivida que se manifestaba con naturalidad, originalidad y contundencia.

Mis esfuerzos para comprender a esta comunidad se canalizaron en dos vertientes. Desde un punto de vista semántico, me ha interesado explorar el significado social

\footnotetext{
2 El origen de los székely es todavía hoy objeto de discusión. Según la versión más popular y legendaria que actualmente los estudiosos han desestimado completamente, los székely serían el reducto de la población de los hunos que al morir Attila permanecieron en la región sur-este de Transilvania. Pero parece que lo más probable es que fuesen los descendientes de una tribu Kabar, turca, que se rebeló contra los khazar y se alió con los húngaros antes de la conquista de las cuencas carpáticas. En cualquier caso, lo que les ha definido históricamente ha sido sobre todo su función militar como defensores de la frontera de Transilvania del Reino de Hungría desde el siglo XII. Como reconocimiento de esta función militar, gozaron de un estatus sui generis: eran hombres libres que no tenían obligaciones de vasallazgo o servidumbre.
} 


\section{perifèria}

Número 4, julio 2006

www.periferia.name

de la comunidad y, desde un punto de vista metodológico, ahondar en la reflexión de la comunidad como una unidad válida para la descripción y comparación de complejos humanos, como una forma concreta de organización humana con dinámicas y especificidades propias.

Los esfuerzos de autores como Redfield (1971) para afrontar la discusión metodológica de la comunidad como un universal cultural y como una totalidad han sido profusamente criticados ${ }^{3}$. Este autor describe la comunidad como un sistema ecológico, como una estructura social y como una biografía típica. El sistema ecológico se define como el conjunto de actividades humanas regulares que reflejan o responden a regularidades de fenómenos naturales. La estructura social serían las interrelaciones funcionales de grupos e instituciones de grupos. $Y$, finalmente, con biografía típica entiende la manera en cómo hombres y mujeres entran y pasan por la estructura social desde su nacimiento hasta su muerte, se trataría de la secuencia de eventos característicos de la vida humana (Redfield 1971: 52-53). Se ha criticado reiteradamente la posición excesivamente culturalista de Redfield al defender que la comunidad como totalidad es una construcción del observador externo que ha de ser confirmada por la autoconciencia interna de sus miembros ${ }^{4}$. Mi estrategia de aproximación a la comunidad ha sido la de focalizar la atención en la práctica empírica de la vida en la comunidad, evitando así que la discusión gravite en torno al observador o sobre aspectos tan escurridizos, desde mi punto de vista, como la 'autoconciencia interna'.

Mi posición es justamente la de entender la comunidad como un complejo humano construido para convivir, de ahí la importancia de observar la práctica diaria de la comunidad. Se trata pues de una propuesta de convivencia original que se distingue por sus valores, por sus medios de subsistencia, por su derecho consuetudinario, por sus instituciones y por las formas relacionales que se establecen entre sus miembros. Estas reglas de convivencia se distinguen y a veces se oponen a otras formas de vivir en sociedad. $Y$ es en este punto donde me interesa reflexionar sobre los aspectos más semánticos de la comunidad, sobre su

\footnotetext{
${ }^{3}$ Se ha puesto de relieve la inadecuación del concepto para análisis transculturales y la dificultad de delimitar el concepto. Pero este es un problema que afronta la antropología en casi todos los conceptos que utiliza, como los del ámbito del parentesco. Para críticas de Redfield ver por ejemplo la reseña de Campbell (1958).

${ }^{4}$ Ver, por ejemplo, John W. Bennett (1956).
} 


\section{perifèria}

Número 4, julio 2006

www.periferia.name

significado social. Me parece importante destacar que la pertenencia a la comunidad viene dada esencialmente por compartir un mismo estilo de vida que se reconoce precisamente en el hecho de vivir en la comunidad. En este caso, no es el nacimiento ni la sangre lo que vincula a la comunidad rural sino el compromiso practicado de un modelo de convivencia, que es el que trato de describir. Esta pertenencia a la comunidad es lo que da derecho, por ejemplo, a los bienes comunales, a los pastos, a los bosques, a la tierra. Es también este compromiso convivencial el que establece obligaciones relacionadas con la reciprocidad y la responsabilidad social.

Varios autores han subrayado el error de considerar a la comunidad como una unidad total, como un sistema completo, que debe ser estudiado con una aproximación holística ignorando la importancia de las relaciones con los centros urbanos y de las élites que no forman parte de la vida del pueblo ${ }^{5}$. Mi posición ha sido la de contrastar precisamente estas relaciones para constatar la existencia de la comunidad como grupo distintivo. De este modo, las relaciones con población urbana, con la Iglesia, con el Estado, tanto el socialista como los post-socialistas, con las reformas agrarias, con las legislaciones que entraban en contradicción con el derecho consuetudinario, o en relación a las políticas nacionalistas, revelan la existencia diferenciada de la comunidad.

Buen ejemplo de ello lo encontramos en la preocupación y dificultad histórica de los Estados para controlar y someter las poblaciones campesinas a los dictados del Estado. A lo largo de la historia vemos qué ocurría cuando el Estado promulgaba leyes desatendiendo los intereses y opiniones de los campesinos. La respuesta más frecuente ha sido que los campesinos simplemente han ignorado estas leyes y han mantenido el derecho consuetudinario. Este derecho expresa un sentido de la justicia y unas bases éticas propias que la comunidad circunscribe (Moshe Lewin 1985).

La crítica a la concepción holística y atomizante de la comunidad retomó los conceptos de part-societies y part-cultures introducidos por Kroeber en 1948. De acuerdo con esta propuesta, las sociedades campesinas constituyen un segmento de una sociedad más amplia y estratificada, y sobre todo, las sociedades

\footnotetext{
${ }^{5}$ C. Von Fürer-Haimendorf (1957), Arthur J. Vidich (1956), Everett C. Hughes (1956), Clifford Geertz
} (1961). 


\section{perifèria}

Número 4, julio 2006

www.periferia.name

campesinas forman parte de tradiciones más amplias, forman parte de civilizaciones (Geertz 1961). Este postulado rompía con el concepto de comunidad como unidad claramente delimitada, al mismo tiempo que afrontaba un problema casi idéntico al que pretendía criticar. Es decir, los límites y la naturaleza de las civilizaciones, por ejemplo de la ideología de castas en la India. Mi forma de aproximación al problema de la delimitación de la comunidad, como ya he señalado, parte de la práctica etnográfica. No me ha interesado tanto la comunidad pensada como la comunidad vivida. $\mathrm{Y}$ es a partir de esta experiencia vital que establezco la comunidad como circunscripción analítica. Es así como la comunidad la forman aquellas personas que viven en ella y de acuerdo a las pautas locales sin que esto signifique que estas personas vivan de forma aislada y completamente autónoma sino considerándolas integradas, más que en civilizaciones, en culturas agrarias, en interacción con Estados y con instituciones más amplias.

Pero los límites de la comunidad rural son efectivamente difusos y a menudo, como en el caso que nos ocupa, se trata de organizaciones descentralizadas. Alwyn D. Rees (1950, en Redfield 1971:6) ya señalaba para el caso de Gales que las comunidades rurales parecían oponerse a cualquier forma de centralización. Que en estas comunidades, cada unidad doméstica y de producción es el único centro para sus miembros y que el tejido de la comunidad, los lazos que unen estos centros se forjan a través del parentesco y de la vecindad ${ }^{6}$. De ahí mi interés en ahondar en el tipo de relaciones de parentesco y vecindad que se establecen.

En este sentido, la terminología de parentesco en el caso que estudio me parece reveladora. Se trata concretamente de la extensión de categorías de parientes colaterales y de la transferencia de términos de dirección de parentesco a noparientes. De hecho, utilizo el concepto de inclusión de parientes en lugar del de extensión, tomando en consideración las críticas que remarcan la confusión entre la fusión terminológica y la fusión semántica. Es decir, se trata de una terminología de dirección y no de referencia, que no define la posición exacta de una persona en

\footnotetext{
${ }^{6}$ La imagen que utiliza Salazar (1996) para describir la comunidad es la de una conglomeración de círculos en intersección cada uno de los cuales está centrado en una familia campesina distinta y contiene todos los participantes de los procesos laborales de esa familia. Salazar destaca como es precisamente la intersección de la esfera del parentesco y la de vecindad la que establece las obligaciones morales entre los miembros de la comunidad. Es decir, las distintas formas de ayuda mutua y de transacciones se dan entre personas que pertenecen a la categoría de parientes o vecinos. Es en base a estas dos categorías que la reciprocidad se ejerce de manera selectiva.
} 


\section{perifèria}

Número 4, julio 2006

www.periferia.name

una red de parentesco, sino que define categorías de personas. Por ejemplo, el término Bátyám (hermano mayor o tío), se aplica a todos los parientes colaterales masculinos y consanguíneos mayores que ego. De esta forma se da un término de dirección (se incluye) a aquellos parientes colaterales que por distancia genealógica no tienen ningún término específico de parentesco. Al mismo tiempo se diferencia según la edad y el sexo, atributos que rigen las relaciones sociales. Lo mismo ocurre con los términos de parentesco que se utilizan para dirigir-se a no-parientes. Por ejemplo, el uso de néni (hermana mayor o tía) para dirigir-se a cualquier mujer mayor que ego. Por lo tanto, a pesar de utilizar el mismo término de parentesco la semántica es completamente diferente cuando se trata de una posición genealógica exacta o cuando se trata de una categoría de personas, ya sean parientes o noparientes $y$, consecuentemente, los derechos y obligaciones que conlleva la relación.

Lo significativo en el uso de términos de parentesco para dirigirse a no-parientes es que sólo se utilizan entre campesinos de la comunidad, nunca con un "extraño". En este caso, la categoría que circunscriben los términos de parentesco es la de miembro de la comunidad. Son términos que demarcan la pertinencia y la exclusión de la comunidad y connotan la solidaridad entre sus miembros:

By alluding to ideal values of kinship and by granting precedence to age over wealth and social position, address usage tends to minimize the possibility of antagonisms that might arise from status inequalities (Vincze 1978:115).

En segundo lugar, las reglas que rigen el uso correcto de estas transposiciones en base a la edad configuran un orden social con derechos y deberes, normas de conducta, jerarquía y todos los valores asociados a este orden. La estrecha relación entre el parentesco, la vecindad y la comunidad que se expresa con el uso de la terminología de parentesco ha sido señalada por otros autores:

Solidarity and reciprocal relations within the village community significantly lowered the risks of households becoming destitute in case of economic failure. Under the influence of village communities, patrilinear kinship ideology gave way to a greater stress on bilateral relations as well as territorial proximity. Households were integrated into a horizontal network of other households that would come to help in case of need. This network included households of women's kin as well as non-related neighboring household and, in the end, the whole village community (Brunnbauer 2003: 196-197). 


\section{perifèria}

Número 4, julio 2006

www.periferia.name

De hecho, la comunidad como institución que regula las relaciones sociales y garantiza seguridad material, fue bien reconocida por el Imperio Otomano para la zona de los Balcanes cuando en la segunda mitad del siglo XIX la tipificó como la unidad administrativa más pequeña con derechos y obligaciones (Brunnbauer 2003: 196-197).

Otro rasgo importante de la comunidad es que se trata de una organización que se caracteriza por lo que podríamos Ilamar la vida común contenida en la visibilidad y tangibilidad cotidiana. Sus habitantes comparten valores, estilos de vida, medios de subsistencia y recursos naturales. Los contenidos compartidos de esta cotidianidad han dado lugar a una idea muy difundida dentro y fuera de la disciplina. Me refiero a la idea de que son sociedades con un alto grado de homogeneidad interna. Según Redfield, por ejemplo, la comunidad se caracteriza por la autosuficiencia, la conciencia de grupo y la homogeneidad interna. Desde mi punto de vista, esta homogeneidad interna existe y se busca sólo en la medida en que garantiza el modelo de convivencia que promueve la comunidad. En otros espacios convivenciales, en cambio, creo que la heterogeneidad de los individuos de la comunidad tiene un margen mucho más amplio de lo que a menudo se cree.

El problema con la idea de sociedades homogéneas aparece cuando se exagera y simplifica la cuestión. De ahí que a menudo se haya construido una imagen falseada de las comunidades como unidades formadas por una masa de individuos indiferenciados que actúan siempre de acuerdo con los dictados de la tradición y la costumbre sin ningún margen de libertad ni de originalidad, a modo de la solidaridad mecánica durkheiminiana. Esta imagen se configura cuando, para remarcar los aspectos que dan apariencia de homogeneidad, se han obviado los conflictos internos $y$ no se han contemplado las posibilidades que brinda la comunidad a sus miembros para desarrollar su individualidad. Precisamente, la relación entre individuo, familia y comunidad ha sido un aspecto que he considerado muy interesante y que un poco más adelante trato de desarrollar. Pero volvamos sobre la idea de homogeneidad como mecanismo que garantiza una convivencia moral:

Accounts of peasant communities stress that in traditional villages people do not compete for prestige with material symbols such as dress, housing, or food, nor do they compete for authority by seeking leadership roles. In 


\section{perifèria}

Número 4, julio 2006

www.periferia.name

peasant villagers one notes a strong desire to look and act like everyone else, to be inconspicuous in position and behaviour. (Foster 1965: 303)

Para Foster, la riqueza es representada como una amenaza y, por esta razón, los mecanismos que otorgan prestigio a los individuos son aquellos que redistribuyen la riqueza acumulada a través de rituales de consumo (por ejemplo bodas o funerales). Kennedy (1966: 1216) respondía a Foster argumentando que, sin negar el papel de los rituales redistributivos, en las comunidades campesinas se da una correlación entre riqueza, prestigio y autoridad. Además, en estos rituales el prestigio va unido a la ostentación de riqueza dejando claro las diferencias entre familias ricas y familias pobres. Por lo tanto, existe una diferenciación social que se expresa públicamente.

Sin lugar a dudas, el trabajo de campo me ha confirmado que tanto la presión o el deseo de uniformidad como las formas de diferenciación social están presentes en la vida cotidiana de la comunidad. Los campesinos expresaban repetidamente la tendencia homogenizadora con la palabra egyforma. Al mismo tiempo, esta misma presión suscita algunas voces críticas muy minoritarias y casi siempre de personas nacidas en el pueblo pero que han emigrado a centros urbanos que denuncian que es precisamente este empeño homogeneizador el que obstaculiza el progreso y la modernización?. Ellos dicen que el problema es que la mayoría de habitantes del pueblo siguen siendo comunistas y no toleran iniciativas individuales. Pero parece que la cuestión es más compleja y más antigua que el socialismo.

Lo interesante es remarcar cómo las diferencias de estatus y riqueza están sometidas a la moral que garantiza una convivencia justa ${ }^{8}$. Entre los mecanismos

\footnotetext{
${ }^{7}$ Estas posiciones remiten al debate sobre si el desarrollo es necesariamente el resultado de prácticas competitivas o si, por el contrario, puede ser también resultado de prácticas cooperativas. En el caso de las comunidades, es fácil comprobar que aquellas personas que cuentan con una red más amplia de vecinos y parientes con los que mantienen relaciones cooperativas o basadas en la reciprocidad son aquellas con más éxito, tanto desde el punto de vista social como económico. Las personas con actitudes más individualistas o más aisladas socialmente, en cambio, corren un riesgo mucho mayor de quiebra o estancamiento económico. Desde esta realidad, la crítica actual al "conservadurismo" campesino responde más a los modelos e ideologías dominantes en la era de la globalización que a la experiencia de la vida en las comunidades. La falsa discrepancia entre actividades económicas basadas en la reciprocidad o la cooperación entre vecinos y parientes y el desarrollo, viene del hecho de que son actividades que se rigen en gran medida por valores morales. Y la idea de que la economía puede ser moral contradice la cultura capitalista que se define justamente como liberada de la jurisdicción de la moral. Ver James Scott (1976), Thompson (1971) o Salazar (1996).

${ }^{8}$ En este sentido, es significativa la posición de los campesinos búlgaros frente al modelo capitalista sintetizada en una cita que recoge Creed: "Let there be private economy, and competition. I am in agreement. But there's no reason why there should be such a big difference between higher and lower. Some difference, of course, but not a gigantic difference. We have to live together." (1998:271).
} 


\section{perifèria}

Número 4, julio 2006

www.periferia.name

de control de desigualdades no solo encontramos rituales redistributivos sino también una estructura social que otorga prestigio en función de la edad antes que de los bienes materiales. Como acabamos de ver, la transferencia de términos de parentesco a no-parientes no hace más que connotar la solidaridad intragrupal minimizando los efectos de la desigualdad material. La envidia y el miedo a ser envidiado es también desde siempre un mecanismo de control de las desigualdades. Durante mi trabajo de campo, este concepto, la envidia, ha aparecido insistentemente para explicar todo tipo de conflictos. De hecho, muchas culturas consideran la envidia como el móvil principal de la brujería y el miedo a ser objeto de brujería, que no es otra cosa que el miedo a ser envidiado, reprime actitudes ostentosas, avariciosas y ambiciosas al tiempo que favorece las más generosas y solidarias. Por ello, la envidia, aparte de ser un sentimiento negativo individual, también es un concepto social positivo para reprimir o censurar actitudes morales que amenacen la cohesión social. En palabras de Lévi-Strauss:

(...) la percepción de la envidia de otro, el temor de ser desposeído mediante la violencia, la angustia que resulta de la hostilidad colectiva, etc., pueden inhibir por completo el goce de un privilegio. La renuncia al privilegio (...). (1969:79)

La desconfianza frente a las desigualdades se relaciona también con el modelo productivo agrario que impera en las comunidades. En un contexto que prácticamente carece de trabajo asalariado y de tecnología y en el que el peso de la producción recae sobre la familia, el número de parientes y su edad determina la capacidad de producción y de consumo de cada unidad doméstica. Así, el ritmo de generación de riqueza o bienes de consumo viene marcado por el ciclo agrario y la capacidad física de los miembros de la unidad doméstica. En esta situación en la cual las políticas agrarias no llegan y donde los precios del mercado no intervienen, la salud y la enfermedad de las personas y los animales y las buenas o malas cosechas son los únicos fenómenos que pueden romper la monotonía de este ritmo humano y estacional $y$, en general, es más frecuente que arruinen a una familia que no que la enriquezcan súbitamente. Así, tanto el ciclo demográfico de una familia como el ciclo agrario y estacional limitan las posibilidades de desigualdades sociales extremas. Es también por este motivo que, como señalan Fél y Hofer 


\section{perifèria}

Número 4, julio 2006

www.periferia.name

(1969: 249), la riqueza repentina despierta suspicacia y, como mínimo, se interpreta como algo irregular.

Estas cuestiones conducen ineludiblemente hacía un tema básico para la comprensión de las comunidades rurales. Se trata del concepto de trabajo. A menudo, los aldeanos cuestionan formas de ganarse la vida que no corresponden con la idea de trabajo que impera en las comunidades agrícolas con frases tales como: "nosotros no nos hemos hecho ricos comprando y vendiendo. Nosotros hemos vivido de nuestro propio trabajo y eso no es nada fácil". Efectivamente, el valor del trabajo es también una cuestión sobre la cual la antropología que se ha dedicado al estudio de sociedades campesinas ha prestado mucha atención. En las comunidades rurales, el trabajo no se considera una simple ocupación sino una forma de vida y una forma de construir una identidad. De hecho, el trabajo es una actividad que, aparte de resolver necesidades materiales, cultiva formas de sociabilidad que no están directamente relacionadas con la esfera económica y un estilo de vida, una humanidad, que llamo arraigo estacional y que se relaciona con la forma de experimentar el tiempo a través del paisaje y el ciclo agrario 9 .

En estas comunidades, la idea y la práctica del trabajo viene muy determinada por el hecho de que la producción descansa sobre las relaciones laborales entre los miembros de la familia. Estas relaciones productivas no se rigen por modelos contractuales o mercantiles sino por los derechos y obligaciones morales propios del ámbito del parentesco. Es decir, que las actividades económicas se desarrollan a través de relaciones sociales que no pertenecen estrictamente o exclusivamente al ámbito económico ${ }^{10}$. Lo mismo ocurre con el significado social que adquieren las propiedades agrícolas. La importancia de la vinculación entre el patrilinaje y la tierra constituye el significado de la propiedad y la transmisión de la tierra más allá de su valor económico. Tal y como remarca Stahl (1986: 27), el cabeza de familia no es un propietario en el sentido moderno de la palabra, sino el administrador de

\footnotetext{
${ }^{9}$ La antropología del tiempo ha trabajado la diferencia y la relación entre el tiempo natural y el tiempo cultural o social. Malinowski ya advertía que la percepción del tiempo de los trobriandeses no descansaba en un conocimiento astronomico sino que dependía sobre todo del ciclo economico de la agricultura. Terradas (1998) subraya la interacción mutua entre estos dos tiempos afirmando que o bien el ritmo social intenta arrastrar el ambiental, como en el caso de los rituales, o bien el ritmo ambiental suscita la memoria social. Eliseu Carbonell (2004) también ha trabajado bastamente la relación entre los ciclos agrarios, los ciclos estacionales y la percepción del tiempo.

10 Salazar (1996) desarrolla de forma brillante estas ideas en su trabajo sobre una comunidad rural irlandesa.
} 


\section{perifèria}

Número 4, julio 2006

www.periferia.name

las posesiones. De hecho, no tiene la libertad de tratarla como una mercadería, tiene el peso moral y la responsabilidad de administrar un patrimonio vinculado tanto a antepasados como a descendientes ${ }^{11}$. De esta forma, ni las relaciones productivas ni las propiedades agrícolas se entienden exclusivamente desde la racionalidad económica. De ahí que la acumulación de riqueza, y la consecuente desigualdad social que conlleva, no sean el único objetivo de las actividades económicas. Es más, encontramos mecanismos que intervienen y limitan la generación de desigualdad.

Otro aspecto interesante del proceso productivo que visibiliza a la comunidad viene del volumen de las propiedades. El hecho de que las unidades domésticas sean propietarias de un pequeño volumen de tierra y de ganado permite, por un lado, la autosuficiencia de la unidad doméstica. Pero, por otro lado, esta misma situación hace necesaria la asociación de todas las unidades domésticas de la comunidad. De esta forma, las necesidades económicas se resuelven con estrategias de cooperación más que con estrategias de mercado. Algunas de estas formas de cooperación están bien instituidas formalmente por el derecho consuetudinario. La kaláka, es un buen ejemplo. Consiste básicamente en el trabajo voluntario que realizan amigos, parientes y vecinos para alguien sin recibir remuneración a cambio. El caso típico es la construcción de una casa o un granero para una pareja recién casada o hacer la cosecha para una persona mayor o incapacitada. Al final de la jornada de trabajo se sirve un festín para todos los participantes. Otras formas de asociación institucionalizadas son las relacionadas con los bienes comunales (bosques, pastos y tierras) o con el ganado, puesto que todas las cabezas de ganado del pueblo se juntan en un solo rebaño.

Pero, aparte de estas formas más institucionalizadas de cooperación y asociación, el quehacer de la comunidad se conforma con un denso tejido de intercambios, ayuda mutua y reciprocidades, que establecen vínculos entre amigos, vecinos, parientes. Como muy bien desarrolla Salazar (1996) esta combinación del trabajo agrícola con

\footnotetext{
11 En Hungría, desde la época medieval, la distinción entre herencia ancestral, avítica, y propiedad adquirida es clara. El benefactor se considera libre de disponer de su propiedad adquirida pero no de la propiedad ancestral que debe pasar necesariamente a los hijos (Fél i Hoffer, 1969:116 y 256; P.H. Stahl, 1986:39, E. Tárkány Szücs, 1980: 611-612). La tierra, por lo tanto, es un patrimonio vinculado y su valor viene del hecho de representar la comunidad de parentesco a la cual se pertenece.
} 


\section{perifèria}

Número 4, julio 2006

www.periferia.name

otras esferas de intercambio social, básicamente el parentesco y la vecindad, otorgan una clara dimensión no económica o, si se prefiere, moral a la producción ${ }^{12}$.

Todas estas cuestiones me han parecido interesantes en la medida en que conforman el contenido propio, el significado social, de la comunidad. Efectivamente, es innegable que existe diferenciación social y económica pero lo que es importante es que esta diferenciación no implique un estilo de vida diferenciado y no amenace el bienestar de la mayoría de la población. Desde este punto de vista, si el criterio central de clase social es el control sobre el trabajo ajeno (Creed 1998: 268) podríamos decir que en muchas comunidades campesinas existe diferenciación social pero no clases sociales.

Todas estas temáticas que he tratado de esbozar hasta aquí hacen que, estando de acuerdo con las aportaciones de Steward y Wolf, me parezcan parciales. Lejos de la orientación culturalista de Redfield que enfatizaba aspectos como la visión del mundo, Steward y Wolf definieron el campesinado como una categoría ocupacional en términos de las actividades económicas de sus miembros (Geertz 1961). Pero los campesinos que viven en una comunidad comparten más que el trabajo agrícola, es más, sus actividades económicas no pueden entenderse como puramente económicas. De ahí mi interés en ahondar en la vida social de la comunidad, en la identidad campesina y todas las prácticas y valores asociados.

En la discusión sobre los valores que rigen las comunidades campesinas se ha exagerado algunos extremos. Ya en 1958, Banfield (1967) hablaba de familismo amoral para expresar la idea de que estas comunidades eran sociedades movidas por el interés individual o familiar, por la envidia y por la desconfianza. En definitiva, sociedades dónde sus habitantes no se identifican con la comunidad. Foster (1965) subrayaba el carácter esencialmente individualista de los campesinos:

People who see themselves in "threatened" circumstances, which the Image of Limited Good implies, react normally in one of two ways: maximum cooperation and sometimes communism, burying individual differences and placing sanctions against individualism; or extreme individualism. Peasant societies seem always to choose the second alternative.

\footnotetext{
${ }^{12}$ Esta idea también la encontramos bien desarrollada y argumentada con el concepto de embeddement de Polanyi para la economía de sociedades primitivas.
} 


\section{perifèria}

Número 4, julio 2006

www.periferia.name

La respuesta crítica al planteamiento de Foster defendió que no se trataba de individualismo sino de familismo. Así, en 1966 Kennedy subrayaba la prevalencia de una fuerte ética familística que subordinaba al individuo y determinaba el comportamiento en las sociedades campesinas (1966: 1214) ${ }^{13}$. A partir de los datos empíricos del trabajo de campo, mi tesis pretende ponderar el lugar del individuo, de la familia y de la comunidad en el entramado social del pueblo compensando algunas de las aportaciones teóricas mencionadas. ¿Qué ocurre, por ejemplo, cuando los intereses individuales y los intereses familiares no coinciden? ¿Cómo se resuelven los conflictos entre sentimientos u opciones individuales e intereses materiales familiares vinculados a estructuras sociales? ¿Cuál es la fuerza de un individuo para revelarse contra poderes o normas locales? ¿Dónde empieza y dónde termina la responsabilidad familiar y la responsabilidad de la comunidad para/con un individuo? Veamos tres ejemplos de ello.

Piroska tuvo que casarse a los dieciséis años con un hombre 20 años mayor que ella: era un buen partido. Su marido era un buen hombre, de buen parecer, trabajador y, sobre todo, pertenecía a una buena familia del pueblo. Estos atributos lo situaban a los ojos de los padres de Piroska como una buena opción y por ello, a pesar de la resistencia de su hija a contraer matrimonio con él, insistieron hasta que ella accedió obedeciendo a sus padres. Ella no lo quería y ellos le respondían aquello de que con el tiempo lo llegaría a querer. Pero el tiempo pasaba y ella no lograba quererlo. Cada noche volvía a la casa de su familia de origen llena de añoranza y tristeza. Estas noches terminaban con el llanto de todos pero, en última instancia, sus padres terminaban aconsejándole que siguiera aguantando. Habían transcurrido seis meses desde el enlace matrimonial cuando Piroska les comunicó a sus padres que había tomado una decisión: ya no iba a volver con su marido, o se quedaba o se mataba. Frente a la amenaza de suicidio, todos, los familiares y la opinión pública, aceptaron la separación. A los 27 años, Piroska se casó de nuevo, esta vez con el hombre que quería y que había elegido.

\footnotetext{
${ }^{13}$ Esta discusión ha sido objeto de preocupación desde los filósofos clásicos. La encontramos ya en $L a$ Política de Aristóteles cuando apunta que "what is common to the greatest number has the least care bestowned upon it. Everyone thinks chiefly of his own, hardly at all of the common interest" (en Ostrom, 1990: 2). Hardin (1968), en su famoso artículo The Tragedy of the Commons, argumenta también que el resultado de la explotación comunal de recursos naturales es necesariamente la degradación del medio ambiente debido a las actitudes individualistas de sus miembros. Para una síntesis y discusión de estos argumentos ver Ostrom (1990).
} 


\section{perifèria}

Número 4, julio 2006

www.periferia.name

Este caso plantea nítidamente la discordancia entre la voluntad individual contrapuesta a la voluntad familiar, los intereses sentimentales contrapuestos a los materiales, los intereses individuales de los contrayentes contrapuestos a los intereses de alianzas políticas o familiares. Nos muestra cómo se resuelve esta tensión en una dura negociación en la que entran en juego varios factores sin que ninguno de ellos se imponga radicalmente o definitivamente: la obediencia debida a los padres, las alianzas matrimoniales entendidas como estrategias para perpetuar posiciones de status y para acumular tierra, y las alianzas matrimoniales como vínculo de sentimientos individuales. Todo ello, lógicamente en un contexto de valores compartidos con la comunidad y prescripciones religiosas que en principio rigen el proceder de los enlaces matrimoniales. En este caso, como en muchos otros, el suicidio o la amenaza de suicidio, parece ser el último recurso de esta negociación. La muerte, en general, se muestra como un recurso muy efectivo para imponer voluntades individuales. Es frecuente, por ejemplo, que la última voluntad de un moribundo haga referencia a la futura vida de sus familiares con sentencias como 'Dejo bajo maldición que esta chica no se traerá a mi propiedad', lo cual era una forma de evitar un enlace matrimonial. Así, la vida de un individuo o su pérdida, tiene la fuerza de desequilibrar poderes, jerarquías y normas.

Este ejemplo, entre muchos otros, ilustra como no es ni el individualismo, ni el familismo, ni la comunidad, lo que dicta el quehacer en la comunidad. La realidad se muestra mucho más flexible, compleja y contradictoria de lo que algunos postulados teóricos de la disciplina proponen. En esa realidad vivida, ninguno de estos niveles (individuo, familia y comunidad) se impone sobre los otros, eso sí: cada uno de estos niveles respeta y reconoce la autoridad y legitimidad de los demás para definir la convivencia. La peculiaridad de la comunidad recae justamente en el peso que adquiere tanto el individuo, como la familia, como la comunidad. Es justamente este diálogo, esta negociación entre partes igualmente respetadas lo que confiere singularidad al devenir de la vida en una comunidad. La eficacia que adquiere cada una de las partes de este trinomio no la encontramos en otras formas de organización y convivencia social donde, dependiendo del contexto, impera normativamente el individualismo o las normas sociales. 


\section{perifèria}

Número 4, julio 2006

www.periferia.name

El segundo caso, plantea los límites de la responsabilidad colectiva en relación a un miembro de la comunidad. Cómo debe responder la familia, los vecinos y la comunidad ante una persona que, a lo largo de su vida, no ha acatado lo que la comunidad esperaba de ella, alguien que no responde a lo que Redfield Ilamaría biografía típica.

En el mes de mayo de 2003, un coma diabético fue suficiente para convertir a Lidi en una persona irreconocible en pocos meses. Lidi provenía de una familia muy humilde, fue huérfana desde muy temprana edad, luego perdió a los hermanos y a su marido en la guerra. Se volvió a casar pero abandonó a su marido a causa de los malos tratos que le propinaba. Estos hechos biográficos y muchos otros configuraron la personalidad de una mujer fuerte, poco diplomática e independiente que carecía de familia, que sembraba, segaba y mantenía su corral sin ayuda de nadie; una mujer que decía no necesitar a nadie, que vivía ignorando los cotilleos locales, sabiendo que la opinión pública no la juzgaba con benevolencia.

Las cosas cambiaron cuando a la edad de 70 años la salud le jugó una mala pasada. Fue entonces cuando empezó a decir que no tenía fuerzas para trabajar, que estaba cansada de vivir y finalmente empezó a vivir muy cerca de la indigencia. La situación de Lidi empezó a ser tema de conversación habitual en el pueblo. Algunos la compadecían, otros se excusaban por no ayudarla y también había quien la criticaba: "Si realmente estuviese tan mal como para no poder trabajar tampoco podría pedir comida". Esa no era la respuesta habitual del pueblo cuando un miembro de la comunidad necesitaba ayuda. En este caso, el desprestigio de Lidi era determinante en esta actitud reticente o insolidaria. Se decía que bebía demasiado, que descuidaba las obligaciones y comportamientos que dictaban los roles de género, que su personalidad no encajaba en el pueblo y no tenía hijos ni familia.

Pero poco a poco, entre la opinión pública, empezaron a ganar peso los comentarios que pedían hacer algo al respecto, que denunciaban que no podía permitirse que una persona, una vecina, un miembro de la comunidad, viviese en estas condiciones en el pueblo. Entonces empezaron las discusiones sobre quien era la persona o la familia que debía responsabilizarse de Lidi. Cualquier momento y lugar era bueno para poner en común la memoria colectiva y trazar las genealogías que 


\section{perifèria}

Número 4, julio 2006

www.periferia.name

señalarían al pariente más próximo que moralmente tendría la responsabilidad de poner fin a la situación de Lidi. Fue así como el centro de las críticas se desplazó desde el juicio a Lidi hasta el de aquellos parientes que se desentendían de ella.

Mientras tanto, Lidi tuvo que vender la vaca y el ternero que tanto le había costado adquirir y mantener, y los vecinos iban cubriendo de forma puntual y espontánea la ayuda que requería. Pero en cualquier caso, esta no era una forma adecuada de resolver la situación: alguien debía asumir la responsabilidad que garantizase su bienestar. Y la presión colectiva empezó a actuar sobre los parientes lejanos y los vecinos de Lidi. Finalmente, una familia vecina que no tenía ninguna necesidad de tierras, propuso un pacto que es bastante habitual: Lidi iría a comer tres veces al día a su casa y ellos se ocuparían de atenderla, a cambio Lidi les cedería sus tierras en usufructo $y$, tras su muerte, las heredarían. Lidi no dudó en aceptar el trato. A pesar de que no eran parientes, esos eran los derechos y obligaciones propias de las relaciones de parentesco. De hecho, algunas personas me decían que eso era una adopción y la misma Lidi heredó la mayor parte de sus tierras de su primo a quien cuidó en su larga enfermedad hasta su muerte ${ }^{14}$.

La solución a la situación de Lidi contiene tanto intereses económicos como responsabilidad moral. Idealmente, el vínculo que debe canalizar la circulación de la tierra es el parentesco. En este sistema de parentesco, el cuidado de los ancianos como obligación moral aparece como el contra servicio de la herencia (Salazar 1998). En este caso, podemos ver como la cultura local transforma una relación de vecindad en lo que podríamos llamar una relación de parentesco ficticio mediante el ejercicio de las obligaciones morales y de las transacciones materiales propias del parentesco. Todo ello ocurre conducido por la presión y movilización de la comunidad que reacciona ante una situación individual que a todos incumbe. Por ello, este ejemplo me parece una buena síntesis empírica del diálogo y la tensión que se da entre individuo, familia y comunidad.

\footnotetext{
${ }^{14}$ En Aragón encontramos una institución parecida, la dació personal, que consiste en darse a alguien o a alguna casa con todos los bienes y para toda la vida, comprometiéndose a trabajar en provecho de ella, a cambio de ser acogido. $Y$, en Cataluña, en la Edad Media, un/a donat/ada era una persona que se acogía a una casa o familia con el derecho de vivir en ella y de ser mantenido y atendido como un miembro de la familia, aportando a cambio sus bienes. Martine Segalen (1986: 140-141) encuentra registros notariales de casos semejantes que incluyen transacciones hereditarias y muestran la solidaridad con personas solteras e incapacitadas para el siglo XIX en Bretaña (Francia).
} 


\section{perifèria}

Número 4, julio 2006

www.periferia.name

El último caso tuvo lugar en el verano de 2005. La tragedia empezó a gestarse unos meses antes, cuando Gergely decidió iniciar un pequeño negocio de piscifactoría con truchas de río. Se trataba de una instalación absolutamente doméstica: un depósito de acero con un pequeño orificio por donde se escapaba el agua constantemente y una manga conectada a un grifo de la vivienda por donde brotaba constantemente agua. Este era el sistema de renovación y oxigenación del agua. La iniciativa pronto se ganó la reprobación de la opinión pública. Decían que a nadie del pueblo se le había ocurrido nunca nada parecido, que haría falta un río con un caudal abundante, que no se podía utilizar el agua potable para los peces, que el agua era un bien escaso, que era de todos y él la malgastaba ${ }^{15}$. Gergely decía que la única motivación que tenía la gente del pueblo para quejarse era la envidia y que en ese lugar nadie toleraba que alguien se ganara la vida o viviese de un modo diferente al del resto de los habitantes.

El caso es que un día, cuando Gergely despertó, se encontró que alguien había cerrado el grifo que alimentaba el depósito y que algunos peces habían muerto. La indignación de Gergely fue tal que no intentó salvar el resto de los peces, solo quería que el culpable lo pagase caro. A pesar de no tener ninguna prueba, no le cabía ninguna duda de quien era el culpable: tenía que ser Jószef, la persona que más le envidiaba. Avisó a la policía que, como es habitual en la región, llegó 11 horas después. Durante todo el día se dedicó a difundir por el pueblo que la policía tomaría las huellas dactilares del grifo y que el culpable debería pagar con tres años de prisión. Gergely es un hombre poderoso y con influencias, de hecho, todo el mundo sabe que es "amigo" de la policía, por ello cuando la policía salió de su casa la pregunta habitual entre el vecindario era si les había pagado.

Tras la marcha de la policía, Gergely fue a buscar a Jószef para decirle que le esperaba a las 6 de la madrugada del día siguiente para llevarlo en coche a la comisaría (él es el único que dispone de coche y la comisaría se encuentra a 8 quilómetros del pueblo). Allí comprobarían si sus huellas dactilares coincidían con las encontradas en el grifo. El problema era que Jószef era una de las personas que hacía chapuzas en el pueblo y justamente unos meses antes había reparado la

15 En el año 2004, con el dinero que se obtuvo de la gestión del bosque comunal y con el trabajo voluntario de los habitantes del pueblo (Közmunka), se consiguió por fin mejorar la canalización del agua para que pudiese llegar a todos. Hasta ese momento mucha gente del pueblo no disponía de agua corriente. 


\section{perifèria}

Número 4, julio 2006

www.periferia.name

instalación de agua de Gergely, por lo cual era seguro que encontrarían sus huellas. Al día siguiente, Jószef no acudió a la cita con Gergely, había dicho a su mujer que por orgullo prefería ir andando. Pero tampoco apareció en la comisaría. Después de mucho buscarlo, de amenazas, de idas y venidas, lo encontraron colgado de un árbol frutal en el jardín trasero de su casa. Gergely huyó desesperado, estaba furioso con Jószef, su muerte había arruinado su vida, decía que él solo pretendía asustarlo y que ahora no podría volver en unos cuantos años al pueblo. Jószef dejaba a una mujer y dos hijos de 10 y 12 años.

El suicidio de Jószef había convertido a la víctima en culpable y al supuesto culpable en víctima. Con un muerto por medio, la policía requirió las facturas de las truchas a Gergely, pero resultó que las transacciones se habían realizado en negro. A Gergely le costó muchas llamadas de teléfono, muchos viajes en coche y 500.000 leis conseguir una factura con fecha retrospectiva por 20 millones de leis. Luego planeó la huída del país cobrándose favores que le debían algunos empresarios locales.

Parece claro que la muerte de Jószef da la vuelta a las relaciones de poder hasta el punto de expulsar a un hombre influyente del pueblo. Esta capacidad le viene dada por el lugar que ocupa en la comunidad. Es justamente el reconocimiento del individuo como miembro de la comunidad lo que confiere eficacia a su gesto. A partir de su muerte, la comunidad reivindica el valor de una vida frente al poder económico o el poder de las influencias con más eficacia de lo que lo harían las leyes. La huída y el miedo de Gergely revelan la capacidad reivindicativa de la comunidad. Él sabe que, incluso un hombre poderoso como él, no puede vivir en la comunidad si esos "simples campesinos", como él diría, le castigan con el vacío social, si en cada interacción social siente el juicio ético de la comunidad que no admite ni indulta a quien, abusando de un poder ilegítimo, negó la vida de uno de sus miembros. Pitt-Rivers decía que Gossip is more powerful than law (Geertz 1961: 14) pero, en este caso, se trata de algo más que chismorreos.

La comunidad se expresa como tal con mucha eficacia y con mecanismos propios vinculados a la esfera moral y social para proteger y reivindicar a sus miembros y 


\section{perifèria}

Número 4, julio 2006

www.periferia.name

para sancionar comportamientos individuales ${ }^{16}$. Es precisamente esta capacidad de un individuo, de un miembro cualquiera de la comunidad, de movilizar a un colectivo con el que comparte la convivencia lo que visibiliza la comunidad como grupo corporativo. Transcurridos unos meses, recibí una carta de alguien del pueblo que me informaba que la mujer de Jószef, cinco meses después de los hechos, se había vuelto a casar sin respetar el periodo de duelo prescriptivo. Parece que este evento mitigaba la tensión.

En este artículo he intentado mostrar que no todas las sociedades campesinas viven en comunidades, ni todos los pueblos son comunidades. La comunidad es un complejo humano que actúa de forma corporativa en aspectos básicos de la subsistencia y la convivencia. En el marco de este patrón de convivencia, el individuo, el vecindario, el parentesco y la comunidad componen un tupido continuum que constituye un entramado social original. La conclusión más importante que queremos apuntar es que ninguno de estos niveles se impone sobre los otros, más bien cada uno de ellos reconoce legitimidad de los demás para definir la convivencia. Como ya hemos señalado, la peculiaridad de la comunidad recae justamente en el peso que adquiere tanto el individuo, como la familia o la comunidad. Es precisamente este diálogo entre las partes, que puede ser más o menos tenso, lo que confiere singularidad al devenir de la vida en una comunidad. Los desenlaces de los conflictos que aparecen cuando los intereses de estos tres niveles no coinciden, no están resueltos de antemano. Se construyen a partir de las acciones singulares de cada una de las partes.

La eficacia que adquiere cada una de las partes de este trinomio no la encontramos en otras formas de organización y convivencia social: así como en nuestra sociedad donde, dependiendo del contexto, impera normativamente el individualismo o las prescripciones formales de carácter estatal o de instituciones ante las cuales el individuo debe someterse. Es así como consideramos, por ejemplo, que la libertad de elección de cónyuge debería imponerse sobre las presiones familiares. En otros

\footnotetext{
${ }^{16}$ En las etnografías de pueblos "primitivos" encontramos muchos casos de suicidios que exigen justicia. Malinowski (1996), por ejemplo, nos describe el caso de Kimai que después de ser acusado públicamente de mantener relaciones con su prima materna, transgrediendo las reglas de la exogamia, se suicida. Pero antes de lanzarse del cocotero expone los motivos que le llevan a quitarse la vida y acusa públicamente a la persona que lo había agraviado, pidiendo venganza.
} 


\section{perifèria}

Número 4, julio 2006

www.periferia.name

conflictos, como en el caso de un vecino incapacitado, en el mejor de los casos, derivaríamos la solución del problema a una institución estatal; o, en un conflicto laboral, acudiríamos a sindicatos o tribunales. De esta forma, la convivencia es mucho más normativa y rígida. Sin embargo es reconocida como margen de lo que llamamos libertad, democracia o individualismo (en el mismo sentido de libertad individual). En cualquier caso, la implicación, la participación y la importancia del individuo, de la familia, del vecindario y de la comunidad no adquieren el mismo significado ni tienen la misma autonomía y eficacia para actuar.

\section{Bibliografía}

Arensberg, Conrad, M. (1961). "The Community as Object and as Sample". American Anthropologist, Vol. 63, No 2, pp. 241-264.

Banfield, Edward C. (1967). The Moral Basis of a Backward Society. New York: The Free Press.

Bennett, John W. (1956). "The Little Community: Viewpoints for the Study of a Human Whole". American Sociological Review, Vol. 21, No. 1, pp. 98-100

Brunnbauer, Ulf (2003). "Decent or Territoriality: Inheritance and Family Forms in the Late Ottoman and Early Post-Ottoman Balkans" en GRANDITS, $\mathrm{H}$ and HEADY, P (Eds) (2003) Distinct Inheritances. Property, Family and Community in a Changing Europe. Vol. 2. Münster: Lit. Max Planck Instutute for Social Anthropology. Halle Studies in the Anthropology of Euroasia. Pp. 181-205.

Campbell (1958). "The Little Community by Robert Redfield". The Philosophical Quarterly, Vol. 8, No. 30, pp. 81-82

Carbonell, Eliseu (2004). Debates acerca de la Antropología del Tiempo. Barcelona: Publicacions de la Universitat de Barcelona.

Creed, Gerald W. (1998). Domesticating Revolution. From Socialist Reform to Ambivalent Transition in a Bulgarian Village. Pennsylvania: The Pennsylvania State University Press. 


\section{perifèria}

Número 4, julio 2006

www.periferia.name

C. Von Fürer-Haimendorf (1957). "Peasant Society and Culture: An Anthropological Approach to Civilization". Man, Vol. 57 , pp. 135.

Fél, Edith \& Hofer, Tamás (1969). Proper peasants. Traditional life in a Hungarian village. Chicago: Aldine.

Foster, George, M. (1965) "Peasant Society and the Image of Limited Good". American Anthropologist, Vol. 67, No 2. pp. 293-315.

Geertz, Clifford (1961). "Studies in Peasant Life: Community and Society". Biennal Review of Anthropology, Vol. 2, pp. 1-41.

Hardin, Garret (1968). "The Tragey of the Commons". Science, 162, pp. 12431248.

Hughes, Everett C. (1956). "The Little Community: Viewpoints for the Study of a Human Whole". The American Journal of Sociology, Vol. 62, No. 1, pp. 98-99.

Kennedy, John, G. (1966). "'Peasant Society and the Image of Limited Good": A Critique". American Anthropologist, Vol. 68, No 5, pp. 1212-1225.

Lévi-Strauss, Claude (1969). Las estructuras elementales del parentesco. Barcelona: Paidós.

Lewin, Moshe (1985). "Customary Law and Russian Rural Society in the PostReform Era". The Russian Review, Vol. 44, pp. 1-19.

Malinowski, B (1996). Crimen y costumbre en la sociedad salvaje. Barcelona: Ariel. Ostrom, Elinor (1990). Governing the Commons. Cambridge: Cambridge University Press.

Redfield, Robert (1971). The Little Community. Peasant Society and Culture. Chicago \& London: The University of Chicago Press .

Salazar, Carles (1996). A Sentimental Economy. Commodity and Community in Rural Ireland. Oxford: Berghahn Books

Salazar, Carles (1998). "Tierra, herencia y patrimonio familiar. Un análisis cultural de los bienes inalienables en la Irlanda rural." en Antropología de la transmisión hereditaria. Simposio Internacional Antropología y herencia. Ferrol: Universidade da Coruña, pp 53-72. 


\section{perifèria}

Número 4, julio 2006

www.periferia.name

Scott, James (1976). The Moral Economy of the Peasant. Rebellion and Subsistence in Southeast Asia. New Haven and London: Yale University Press.

Segalen, Martine (1986). 'Avoir sa part': dibiling relations in partible inheritance Brittany, en Medick, Hans and Warren Sabean, David (Eds.), 1986, Interest and emotion. Essays on the study of family and kinship. Cambridge University Press. Pp. 129-144.

Stahl, Paul H. (1986). Household, village and village confederation in southeastern Europe. New York: Columbia University Press.

Tárkány Szücs (1980). "Legal folk customs in the order of succession of peasants in Hungary (1700-1945)". Agrártörténeti szemle. Historia Rerum Rusticarum, XXII.

Terradas, Ignasi (1998) "CIRCA Antropología del tiempo y la inexactitud". Anales de la Fundación Joaquín Costa, no 14, pp. 233-253.

Thompson, E.P (1971). "The Moral Economy of the English Croad in the Eighteenth Century". Past and Present, no 50, pp. 76-136.

Vidich, Arthur J. (1956). "The Little Community: Viewpoints for the Study of a Human Whole". Man, Vol. 56, pp. 112-113.

Vincze, Lajos (1978). "Kinship Terms and Address in a Hungarian Speaking Peasant Community in Rumania". Pennsylvania: Ethnology, n¹7: 101-117. 